\title{
Primary intrapulmonary solitary fibrous tumours
}

\author{
XIA LIN $^{1 *}$, YINGMING XIANG $^{1 *}$, HONGCAN SHI ${ }^{2 *}$ and FANGBIAO ZHANG ${ }^{1}$ \\ ${ }^{1}$ Department of Cardiothoracic Surgery, Lishui Center Hospital, Lishui, Zhejiang 323000; ${ }^{2}$ Department of \\ Cardiothoracic Surgery, Clinical College, Yangzhou University, Yangzhou, Jiangsu 225001, P.R. China
}

Received March 31, 2017; Accepted September 18, 2017

DOI: $10.3892 / \mathrm{ol} .2018 .7798$

\begin{abstract}
Due to the extreme rarity of primary intrapulmonary solitary fibrous tumours (SFTs), their clinical course, imaging characteristics, diagnosis, treatment and prognosis are poorly understood. The present study therefore assessed the diagnosis and management of primary intrapulmonary SFTs and systematically reviewed previously reported cases in the literature. A total of 5 patients who underwent resection for primary intrapulmonary SFTs were enrolled in the present study and their clinical course, tumour characteristics, management and survival were assessed in this retrospective study. Relevant studies regarding primary intrapulmonary SFTs were searched using PubMed and tumour characteristics, clinicopathologic features, therapeutic strategy and survival outcomes were reviewed. Of the 5 cases, all were males, with a mean age of 57.6 years (range, 37-68 years). All patients were asymptomatic and were identified incidentally on routine computed tomography examination. A total of 3 patients underwent thoracotomy and 2 patients underwent video-assisted thoracoscopic surgery. All tumours were completely resected. Postoperative haemorrhage occurred in 1 patient and he received surgical intervention for haemostasis. The average hospital stay was 15 (4-22) days, and no mortality occurred. The mean length of the postoperative follow-up was 37.6 (1-67) months. One patient was lost to follow-up, and 4 patients were asymptomatic. A total of 19 studies were identified from database searches. They included a total of 45 patients: Twenty-three males and 22 females (mean age, 59.4 years; range, 7-81 years). A total of 12 patients were asymptomatic, and pain and coughing were the major symptoms. Five, one, two, four, and 17 tumours occurred in the right upper lobe, right middle lobe, right lower lobe, left upper lobe and left lower lobe, respectively.
\end{abstract}

Correspondence to: Dr Fangbiao Zhang, Department of Cardiothoracic Surgery, Lishui Center Hospital, 289 Kuocang Road, Lishui, Zhejiang 323000, P.R. China

E-mail: zhangfangbiao9@126.com

*Contributed equally

Key words: solitary fibrous tumours, pulmonary, surgery, systematic review
A total of 39 patients underwent surgery, 1 patient underwent radiotherapy, and 1 patient underwent radiofrequency ablation. A total of 22 patients were followed up and the mean length of the postoperative follow-up was 48 (1-168) months. One patient was diagnosed with chest wall metastases, and 5 patients succumbed to mortality. To conclude, primary intrapulmonary SFTs are extremely rare and typically identified incidentally. The present findings indicated that the left lower lobe was the most common site location and complete surgical resection is a safe and effective treatment.

\section{Introduction}

A solitary fibrous tumour (SFT) is a rare, slow-growing, mesenchymal neoplasm arising from the pleura, which is unrelated to asbestos exposure or cigarette smoking (1) and was initially described in 1931 (2). Over the past 80 years, SFTs have been identified in numerous extrapleural locations, including the nasal cavity (3), breast (4), stomach (5), bronchus (6), head and neck (7), liver (8), oesophagus (9), pelvic (10), pancreas (11), prostate (12), orbit (13), central nervous system (14), parotid gland (15), kidney (16), lung (17), sella turcica (18), heart (19), conus medullaris (20), omentum (21), infratemporal fossa (22), bladder (23), soft tissues of the extremities (24), palatine tonsil (25), diaphragm (26), mesentery (27), lumbar spine (28), thymus (29), oral cavity (30), spermatic cord (31), thyroid (32), rectum (33), salivary glands (34), retroperitoneum (35), larynx (36), trachea (37), adrenal gland (38), female genital tract (39), periosteum of bone (40), mediastinum (41) and hypopharynx (42).

To our knowledge, SFTs are extremely rare in the lung (43). There are few detailed case reports concerning the clinical course, imaging characteristics, diagnosis, treatment and prognosis of primary intrapulmonary SFTs. The main purpose of the present study was to report our experience with the diagnosis and management of primary intrapulmonary SFTs and to systematically review previously reported cases in the literature.

\section{Patients and methods}

We retrospectively reviewed the records of 5 patients with primary intrapulmonary SFTs who underwent surgical resection at the Department of Cardiothoracic Surgery, Lishui Center Hospital (Lishui, China), and Clinical College of Yangzhou University, (Yangzhou, China), between January 2000 and 
January 2016. Age, sex, medical history, clinical presentation, diagnostic methods, intraoperative findings, postoperative complications and outcome were retrieved from hospital records. Meanwhile, relevant studies regarding intrapulmonary SFTs were searched via PubMed from January 1990 to January 2016. The text words and MeSH terms 'Solitary fibrous tumours', 'Intrapulmonary', and 'Lung' were used. Tumour characteristics, clinicopathologic features, therapeutic strategy and survival outcomes were reviewed, and these data were tabulated.

\section{Results}

Report of cases. Of the five cases, all were males, with a mean age of 57.6 years (range, 37-68 years). Two patients (nos. 2 and 5) had history of hypertensive disease. One patient (no. 2) had history of diabetes mellitus. One patient (no. 1) had history of bronchial asthma. One patient (no. 3) had history of nodular goitre. The remaining patient (no. 4) had no history of any disease. All patients were asymptomatic, and their tumours were discovered incidentally on routine computed tomography $(\mathrm{CT})$ examination. Contrast-enhanced $\mathrm{CT}$ of the chest revealed a lung mass with no calcification or any fatty tissue (Fig. 1). One, one, one and two tumours occurred in the right lower, left upper, right upper and left lower lung, respectively. Three patients (nos. 1-3) were preoperatively diagnosed with spindle cell tumour by CT-guided percutaneous aspiration biopsy. Other examinations, including pulmonary function, echocardiogram, electrocardiogram, coagulation function and blood routine examination, were normal. The serum levels of $\mathrm{Na}^{+}, \mathrm{K}^{+}, \mathrm{Cl}^{-}, \mathrm{Ca}^{2+}, \mathrm{Mg}^{2+}$ were all within reference range. Serum carbohydrate antigen, carcino-embryonic antigen, squamous cell antigen and neuron-specific enolase were within normal limits. No evidence of metastasis was found via head magnetic resonance imaging (MRI) and abdominal ultrasound.

One patient underwent tumour enucleation though thoracotomy (no. 1), one patient underwent upper left lobectomy associated with lymph node dissection involving radical dissection of the mediastinum (no. 2), and one patient underwent tumour resection associated with bilateral subtotal thyroidectomy (no. 3). The remaining two patients underwent tumour enucleation via video-assisted thoracoscopic surgery (VATS) (nos. 4 and 5) (Figs. 2 and 3). Data of the clinical features are shown in Table I.

The haematoxylin and eosin (H\&E) stain showed a rich variety of spindle cells and amorphous areas of collagen (Fig. 4). Immunohistochemical reactions of the tumour cells were strongly positive for B-cell lymphoma (Bcl)-2 (Fig. 5) and cluster of differentiation (CD)34 (Fig. 6). Tumour cells were positive for vimentin (nos. 4 and 5) (Fig. 7) and CD99 (nos. 2-5) (Fig. 8). The tumour cells were negative for CD117, desmin, smooth muscle actin (SMA), epithelial membrane antigen and S-100. Following an immunohistochemical-analysis-based study, the diagnosis of intrapulmonary SFTs was made.

Postoperative haemorrhage occurred in one patient (no. 1), and he received surgical intervention for haemostasis. The average time of intrathoracic drain was 3.6 (1-9) days. The average hospital stay was 15 (4-22) days, and

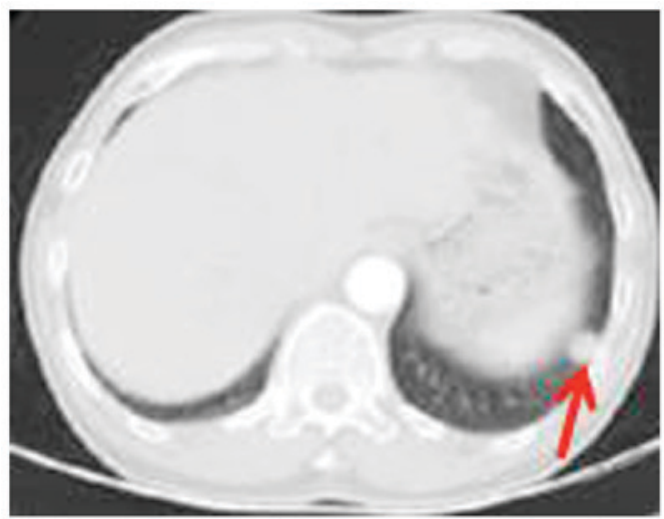

Figure 1. CT scan of the chest demonstrated a $1.5 \times 1.5 \mathrm{~cm}$ left lung mass (red arrow). CT, computed tomography.

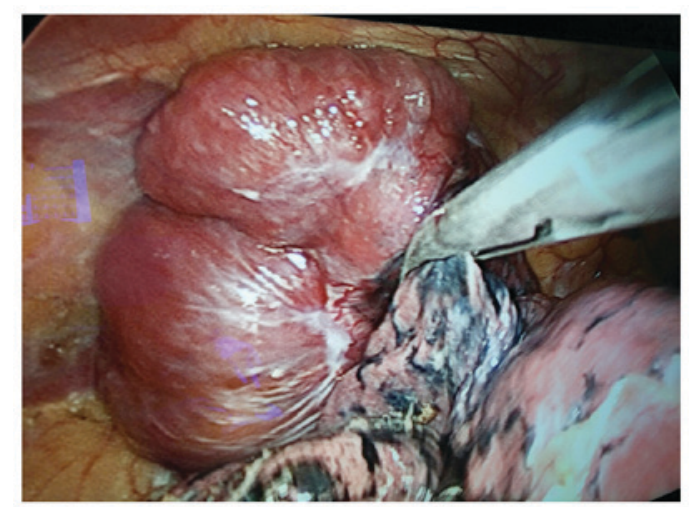

Figure 2. Surgical procedure, partially dissected right upper lung mass.

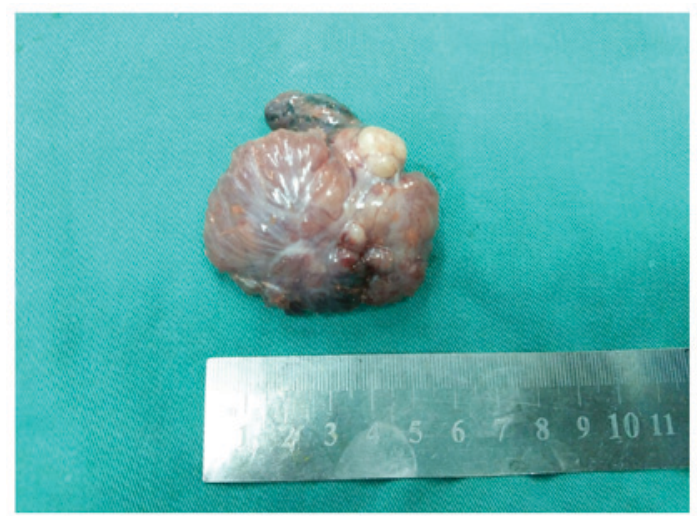

Figure 3. Surgical specimen of $5.5 \times 5 \times 5 \mathrm{~cm}$ and weighing $325 \mathrm{~g}$.

no mortality occurred. All patients were discharged from the hospital following an uneventfully recovery. The mean length of the postoperative follow-up was 37.6 (1-67) months. One patient was lost to follow-up, and four patients were asymptomatic.

Published case study findings. Nineteen articles were identified from the searches of databases (17,43-59) (Table II). They had a total of 45 patients: Twenty-three males and 22 females. The mean age was 59.4 years, ranging from 7 to 81 years. Twelve patients were asymptomatic, and pain 
Table I. Patient characteristics and treatment history in our study.

\begin{tabular}{|c|c|c|c|c|c|}
\hline Features & Patient no. 1 & Patient no. 2 & Patient no. 3 & Patient no.4 & Patient no. 5 \\
\hline Sex & Male & Male & Male & Male & Male \\
\hline Age (years) & 37 & 59 & 59 & 65 & 68 \\
\hline Presentation & Asymptomatic & Asymptomatic & Asymptomatic & Asymptomatic & Asymptomatic \\
\hline Previous history & Bronchial asthma & $\begin{array}{l}\text { Hypertensive disease, } \\
\text { diabetes mellitus }\end{array}$ & Nodular goiter & No & $\begin{array}{l}\text { Hypertensive } \\
\text { disease }\end{array}$ \\
\hline Paraneoplastic syndrome & No & No & No & No & No \\
\hline Location of lesions & Right lower lobe & Left lower lobe & Left upper lobe & Left lower lobe & $\begin{array}{l}\text { Right upper } \\
\text { lobe }\end{array}$ \\
\hline Surgical strategy & Thoracotomy & Thoracotomy & $\begin{array}{l}\text { Thoracotomy + } \\
\text { bilateral } \\
\text { subtotal } \\
\text { thyroidectomy }\end{array}$ & VATS & VATS \\
\hline Surgical procedures & $\begin{array}{l}\text { Adequate wedge } \\
\text { resection }\end{array}$ & $\begin{array}{l}\text { Left lower } \\
\text { lobectomy associated } \\
\text { with lymph } \\
\text { node dissection }\end{array}$ & $\begin{array}{l}\text { Left upper } \\
\text { lobectomy }\end{array}$ & $\begin{array}{l}\text { Adequate wedge } \\
\text { resection }\end{array}$ & $\begin{array}{l}\text { Adequate } \\
\text { wedge } \\
\text { resection }\end{array}$ \\
\hline Operating time (min) & 100 & 120 & 150 & 75 & 35 \\
\hline Blood loss (ml) & 200 & 300 & 100 & 5 & 50 \\
\hline Size of lesion $(\mathrm{cm})$ & $2.5 \times 3.0$ & $7 \times 5$ & $6.5 \times 3$ & $1.5 \times 1.5$ & $4 \times 3$ \\
\hline Postoperative complication & $\begin{array}{l}\text { Postoperative } \\
\text { hemorrhage }\end{array}$ & no & No & No & no \\
\hline Hospital stay (days) & 22 & 18 & 22 & 4 & 9 \\
\hline $\begin{array}{l}\text { Time of intrathoracic } \\
\text { drain (days) }\end{array}$ & 9 & 5 & 1 & 1 & 2 \\
\hline Cellular pattern & Spindle & Spindle & Spindle & Spindle & Spindle \\
\hline Mitotic count & $<1 / 10 \mathrm{HPF}$ & $>10 / 10 \mathrm{HPF}$ & $<5 / 10 \mathrm{HPF}$ & $<1 / 10 \mathrm{HPF}$ & $<5 / 10 \mathrm{HPF}$ \\
\hline CD34 & + & + & + & + & + \\
\hline CD99 & - & + & + & + & + \\
\hline Bcl-2 & + & + & + & + & + \\
\hline Vimentin & - & - & - & + & + \\
\hline Desmin & - & - & - & - & - \\
\hline S-100 & - & - & - & - & - \\
\hline SMA & - & - & - & - & - \\
\hline Diagnosis & Benign & Malignant & Benign & Benign & Benign \\
\hline Follow up (months) & 38 & 67 & 55 & 27 & 1 \\
\hline Recurrence & Unknown & No & No & No & No \\
\hline Present status & Unknown & NED & NED & NED & NED \\
\hline
\end{tabular}

NED, no evidence of disease; VATS, video-assisted thoracoscopic surgery; CD, cluster of differentiation; Blc-2, B-cell lymphoma 2; SMA, smooth muscle actin.

and cough were the major symptoms. Five, one, two, four, and seventeen tumours occurred in the right upper lobe, right middle lobe, right lower lobe, left upper lobe and left lower lobe, respectively. Thirty-nine patients underwent surgery, one patient underwent radiotherapy, and one patient underwent radiofrequency ablation. Twenty-two patients were followed up, and the mean length of the postoperative follow-up was 48 (1-168) months. One patient was diagnosed with chest wall metastases. Five patients died (Table III).
Pathologic and immunohistochemical features. Twenty-eight of 32 cases showed low mitotic counts $(0-5 / 10$ HPF), 1 of 32 had a middle mitotic count (0-6/10 HPF), and 3 of 32 showed high mitotic counts (5-10/10 HPF). Immunohistochemical staining analyses were performed in 28 cases. Twenty-four of 28 cases were CD34-positive. Ten of 13 cases were CD99-positive. Fourteen of 15 cases were Bcl-2 positive. Fourteen of 16 cases were vimentin positive. Five of 17 cases were smooth muscle antibody (SMA)-positive. Two of 9 cases were epithelial membrane antigen (EMA) 


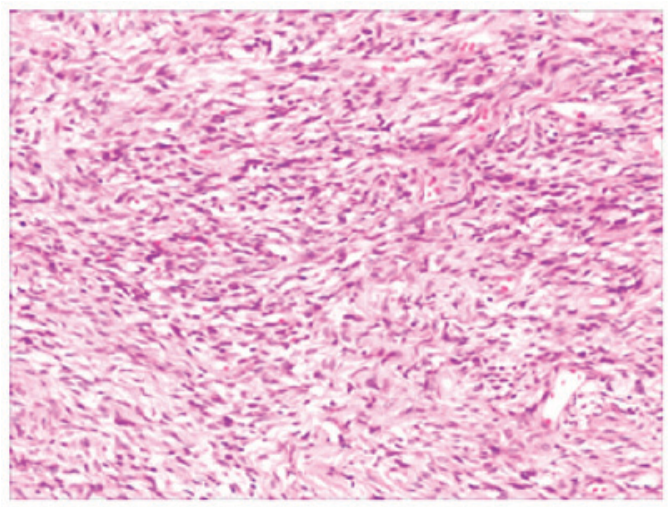

Figure 4. Haematoxylin and eosin staining showed a rich variety of spindle cells and amorphous areas of collagen (magnification, x100).

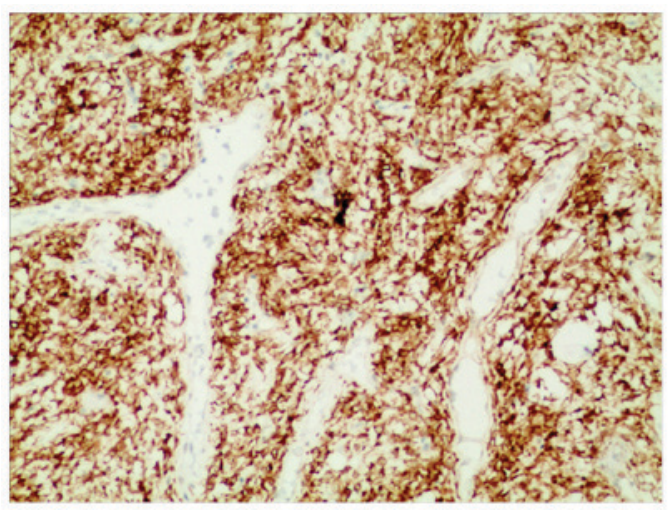

Figure 5. The immunohistochemical reactions for Bcl-2 were positive (magnification, x100). Bcl-2, B-cell lymphoma-2.

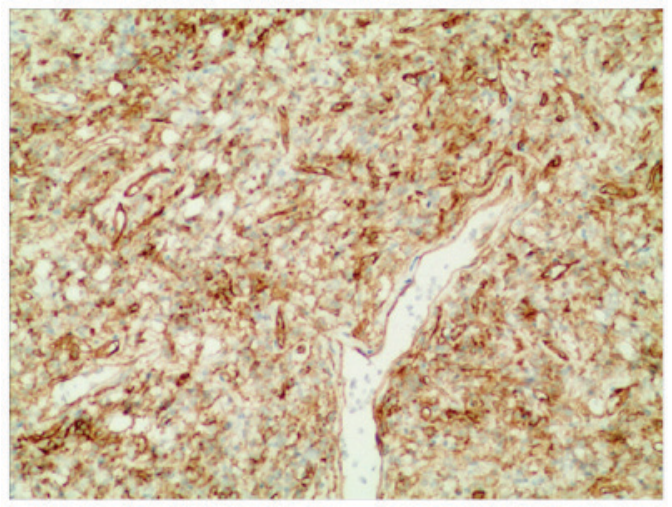

Figure 6. The immunohistochemical reactions for $\mathrm{CD} 34$ protein were positive (magnification, $\mathrm{x} 100$ ). $\mathrm{CD}$, cluster of differentiation.

positive. Eight of 9 cases were mib-monoclonal antibody-1 (MIB-1)-positive (Table IV).

\section{Discussion}

SFTs are rare, mesenchymal neoplasms initially described in the pleura but have since been discovered in nearly every anatomic location (61). Klemperer and Rabin (62) reported 5 cases of primary pleural neoplasms in 1931 and proposed that SFT was of submesothelial origin. However, in the

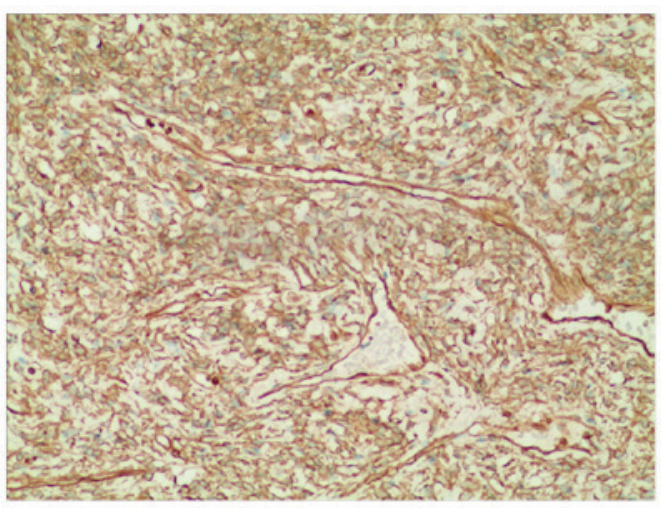

Figure 7. The immunohistochemical reactions for vimentin protein were positive (magnification, x100).

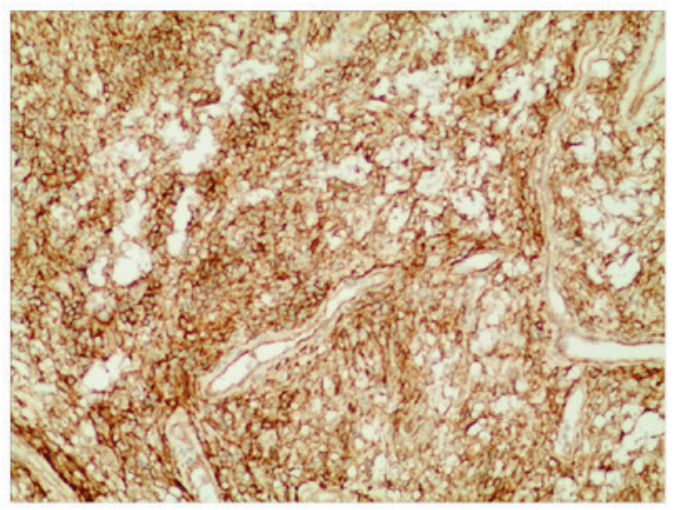

Figure 8. The immunohistochemical reactions for CD99 protein were positive (magnification, $\mathrm{x} 100$ ). $\mathrm{CD}$, cluster of differentiation.

subsequent decades, on the basis of immunohistochemical analyses and ultrastructural features, it is now recognized that SFTs arise from primitive fibroblast-like cells in connective tissue (61). SFTs, to our knowledge, most often occur in the pleura. They can be rarely found in the lung, central nervous system, kidney and other extrapleural sites. Via searches of databases, a total of 45 patients with intrapulmonary SFTs were found.

Intrapulmonary SFTs are usually found incidentally and may be associated with chest pain and cough. Seventeen patients (5 in our study and 12 in published literature) were asymptomatic and were discovered incidentally. Two patients presented with pain, and two patients presented with cough. Of note, few patients with SFTs present with refractory hypoglycaemia, which is a paraneoplastic syndrome that secretes a prohormone form of insulin-like growth factor-II (IGF-II), referred to as the Doege-Potter syndrome (DPS).

Due to their atypical clinical and radiographic appearance as a common lung tumour, the diagnosis of intrapulmonary SFTs presents unique challenges. Imaging examinations, including chest X-rays, CT and MRI, are used for assessing intrapulmonary SFTs. There are limited data on X-rays and CT imaging features of intrapulmonary SFTs. The available data show that intrapulmonary SFTs are well-defined ovoid or round pulmonary nodules on chest X-rays and CT scanning, but they are non-specific. The PET-CT findings of SFTs have 


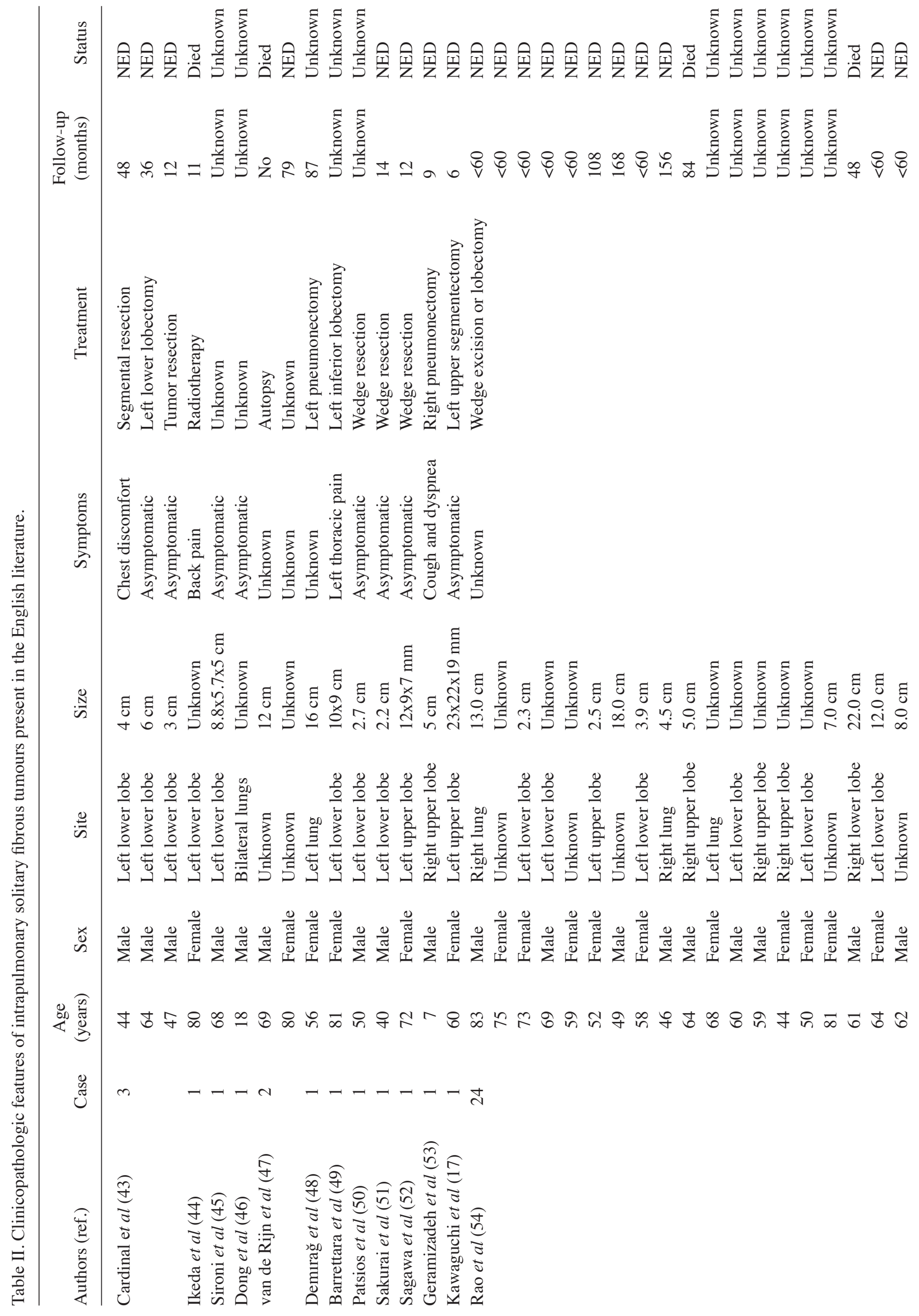




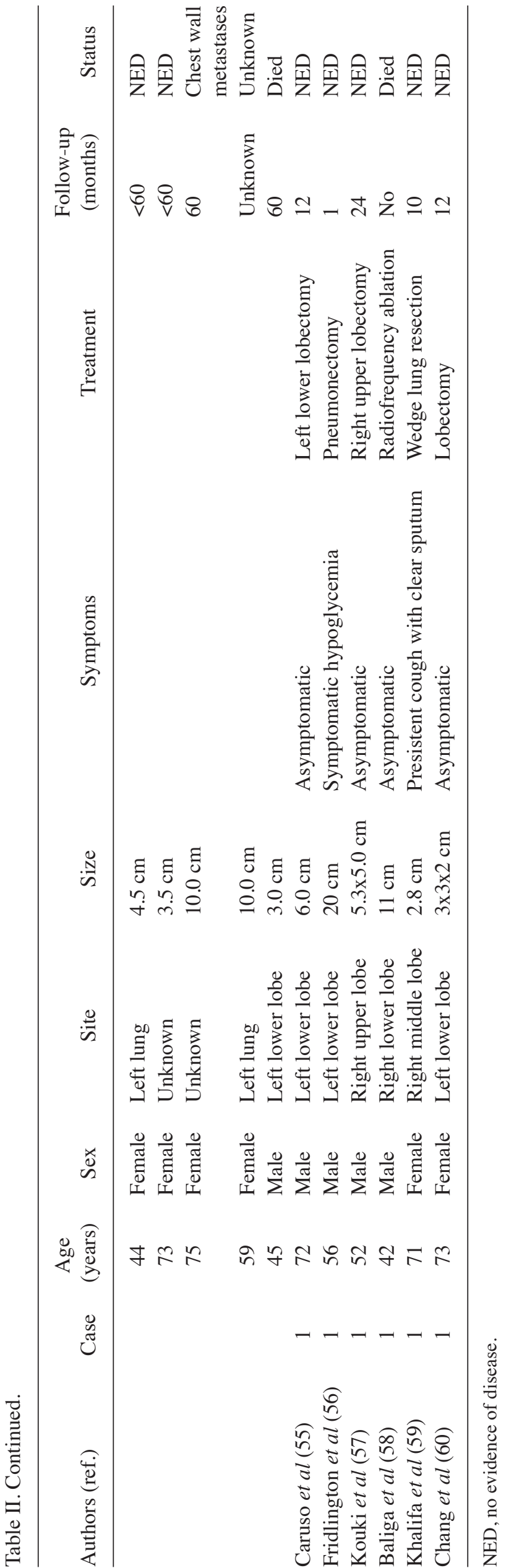

Table III. Characteristics of the primary intrapulmonary solitary fibrous tumors present in the English literature.

\begin{tabular}{lc}
\hline No. of studies & 19 \\
\hline No. cases & 45 \\
Age (years) & \\
Mean & 59.4 \\
Range & $7-81$ \\
Tumor sizes (cm) & \\
Mean & 8.2 \\
Range & $2-23$ \\
Sex & \\
Male & \\
Female & $23(51.1 \%)$ \\
Symptoms & $22(48.9 \%)$ \\
Asymptomatic & 18 \\
Pain & $12(66.7 \%)$ \\
Cough & $2(11.1 \%)$ \\
Other & $2(11.1 \%)$ \\
Localization & $2(11.1 \%)$ \\
Right upper lobe & 29 \\
Right middle lobe & $5(17.2 \%)$ \\
Right lower lobe & $1(3.5 \%)$ \\
Left upper lobe & $2(6.9 \%)$ \\
Left lower lobe & $4(13.8 \%)$ \\
Treatment & $17(58.6 \%)$ \\
Surgery & 41 \\
Radiotherapy & $39(95.2 \%)$ \\
Radiofrequency ablation & $1(2.4 \%)$ \\
& $1(2.4 \%)$ \\
\hline
\end{tabular}

been rarely reported. PET-CT is a useful tool for evaluating the size, regional invasion and distant metastasis of a tumour. Yan et al (63) have reported a malignant SFT with mildly increased FDG uptake. Dong et al (46) have reported a benign SFT with intense FDG uptake. The clinical behaviour of the tumour may be predicted based on PET-CT findings, and FDG uptake degree may be related to the tumour's aggressive behaviour (46). An intrapulmonary SFT may be identified by CT-guided percutaneous aspiration biopsy. Caruso et al (55) operated on a pulmonary mass CT-guided FNA cytology biopsy. The FNA cytologic specimen contained spindle cells. Furthermore, FNA cytology, proper clinical and radiologic findings are helpful in narrowing the diagnostic possibilities and making tentative pathologic diagnoses. However, spindle-shaped cells also appear in fibrosarcoma, leiomyosarcoma, schwannoma and others. Therefore, the diagnosis of SFTs may not be identified without immunohistochemical staining. The differential diagnosis of intrapulmonary SFT includes numerous malignant and benign tumours, including pulmonary adenofibroma, benign neural neoplasms, leiomyoma, leiomyosarcoma, synovial sarcoma, spindle cell thymoma, spindle cell carcinoid tumour, nerve sheath tumour, fibrosarcoma, sarcomatoid carcinoma, and sarcomatoid mesothelioma (54). To our knowledge, positive CD34, 
Table IV. Pathologic and immunohistochemical features presented in the English literature.

\begin{tabular}{|c|c|c|}
\hline Author & Mitotic count & Immunohistochemistry \\
\hline Sironi et al (45) & NA & $\mathrm{CD} 34^{+}, \mathrm{CD} 99^{+}$ \\
\hline Dong et al (46) & NA & 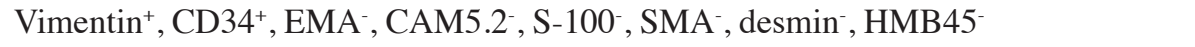 \\
\hline van de Rijn et al (47) & NA & $\mathrm{CD}^{2} 4^{+}, \mathrm{SMA}^{-}, \mathrm{MSA}^{-}$, desmin ${ }^{-}, \mathrm{AE}^{-}, \mathrm{CAM}^{-}$ \\
\hline Demırağ et al (48) & 2/10 HPF & $\mathrm{CD} 44^{+++}, \mathrm{MMP}^{-} 2^{+}$ \\
\hline Barrettara et al (49) & 2/10 HPF & 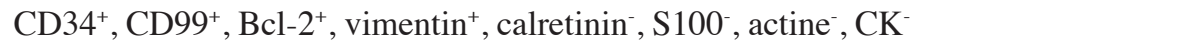 \\
\hline Patsios et al (50) & NA & Vimentin $^{+}, \mathrm{CD} 34$ : focal ${ }^{+}, \mathrm{CK}^{-}, \mathrm{S}-100^{-}, \mathrm{SMA}^{-}$ \\
\hline Sakurai et al (51) & NA & Vimentin $^{+}, \mathrm{CD}_{3} 4^{+}, \mathrm{Bcl}_{-} 2^{+}, \mathrm{CK}^{-}$, desmin $^{-}, \mathrm{SMA}^{-}, \mathrm{S}-100^{-}$ \\
\hline Sagawa et al (52) & Rare & $\mathrm{CD} 4^{+}, \mathrm{TTF}^{-} 1^{-}, \mathrm{MIB}^{-} 1^{-}$ \\
\hline Geramizadeh et al (53) & 0/10 HPF & Vimentin $^{+}, \mathrm{CD}_{3} 4^{+}, \mathrm{Bcl}-2^{+}, \mathrm{CK}^{-}$, desmin $^{-}, \mathrm{SMA}^{-}, \mathrm{S}-100^{-}$ \\
\hline Kawaguchi et al (17) & NA & $\mathrm{CD}^{+} 4^{+}$, calretinin ${ }^{-}, \mathrm{SMA}^{-}, \mathrm{S}-100^{-}$ \\
\hline \multirow[t]{24}{*}{ Rao et al (54) } & 2-5/10 HPF & NA \\
\hline & $2-5 / 10 \mathrm{HPF}$ & 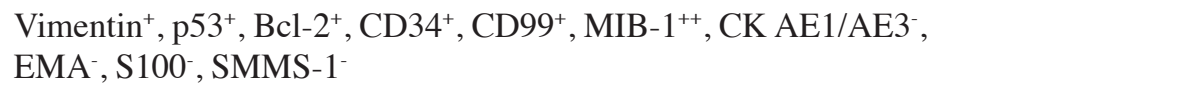 \\
\hline & $<1 / 10 \mathrm{HPF}$ & NA \\
\hline & $<1 / 10 \mathrm{HPF}$ & NA \\
\hline & $<1 / 10 \mathrm{HPF}$ & NA \\
\hline & $<1 / 10 \mathrm{HPF}$ & NA \\
\hline & 2-5/10 HPF & 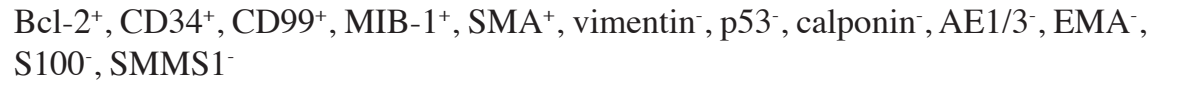 \\
\hline & $<1 / 10 \mathrm{HPF}$ & $\mathrm{Bcl}_{-2}{ }^{+}, \mathrm{CD}_{3} 4^{+}, \mathrm{CK} \mathrm{AE} 1 / 3^{-}, \mathrm{SMA}^{-}$ \\
\hline & 2-5/10 HPF & NA \\
\hline & $<1 / 10 \mathrm{HPF}$ & $\mathrm{CD} 4^{+}, \mathrm{CD} 9^{+}, \mathrm{MIB}^{-} 1^{+}, \mathrm{SMA}^{-}, \mathrm{CK} \mathrm{AE} 1 / 3^{-}$ \\
\hline & $<1 / 10 \mathrm{HPF}$ & NA \\
\hline & 2-5/10 HPF & NA \\
\hline & $<1 / 10 \mathrm{HPF}$ & NA \\
\hline & $<1 / 10 \mathrm{HPF}$ & NA \\
\hline & $<1 / 10 \mathrm{HPF}$ & NA \\
\hline & $<1 / 10 \mathrm{HPF}$ & NA \\
\hline & 2-5/10 HPF & 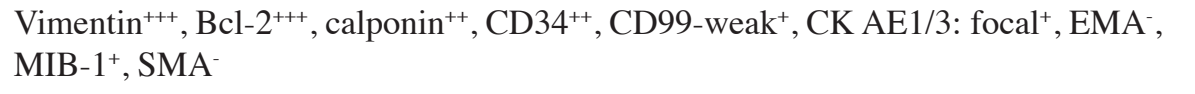 \\
\hline & $<1 / 10 \mathrm{HPF}$ & $\mathrm{Bcl}^{2+++}, \mathrm{CD}^{+} 4^{+}, \mathrm{CD}^{+} 9^{+}, \mathrm{MIB}-1^{+}, \mathrm{SMA}^{+}, \mathrm{CK}$ AE1/3- ${ }^{-}$vimentin ${ }^{-}$, calponin ${ }^{-}, \mathrm{EMA}^{-}$, \\
\hline & 2-5/10 HPF & 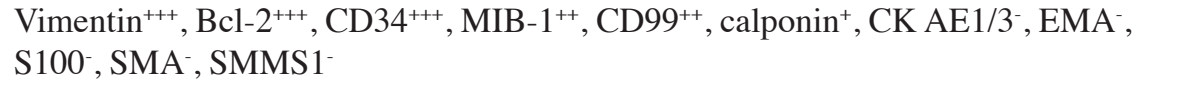 \\
\hline & $<1 / 10 \mathrm{HPF}$ & 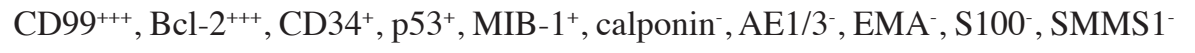 \\
\hline & $<1 / 10 \mathrm{HPF}$ & 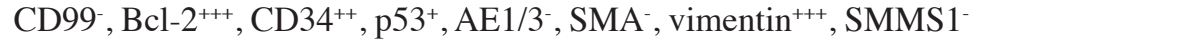 \\
\hline & $5-10 / 10 \mathrm{HPF}$ & $\mathrm{Bcl}_{-2}{ }^{+}, \mathrm{CD}_{3} 4^{+}, \mathrm{CD} 99^{+}, \mathrm{SMA}^{+}, \mathrm{CK} \mathrm{AE} 1 / 3^{-}$ \\
\hline & $>10 / 10 \mathrm{HPF}$ & 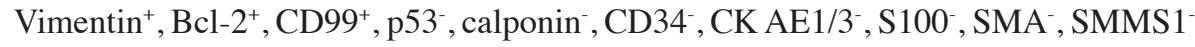 \\
\hline & $>10 / 10 \mathrm{HPF}$ & 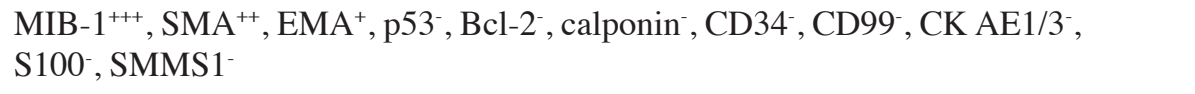 \\
\hline Caruso et al (55) & 0-6/10 HPF & 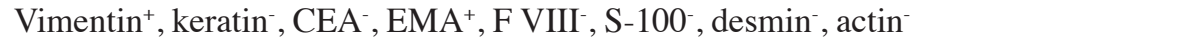 \\
\hline Fridlington et al (56) & 1-2/10 HPF & $\mathrm{CD}^{4} 4^{+}$, vimentin $^{+}, \mathrm{S}-100^{-}$ \\
\hline Kouki et al (57) & 3-4/10 HPF & $\mathrm{CD} 4^{+}$ \\
\hline Baliga et al (58) & 0/10 HPF & 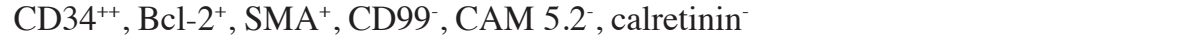 \\
\hline Khalifa et al (59) & NA & $\mathrm{CD}^{+} 4^{+}$, vimentin ${ }^{+}, \mathrm{S}-100-, \mathrm{CK}^{-}, \mathrm{F}^{-} \mathrm{VIII}^{-}, \mathrm{MSA}^{-}, \mathrm{SMA}^{-}$ \\
\hline Chang et al (60) & NA & $\mathrm{CD}^{+} 4^{+}$, vimentin ${ }^{+}, \mathrm{S}-100^{-}$, desmin $^{-}, \mathrm{CEA}^{-}, \mathrm{a} 1-\mathrm{ACT}^{-}, \mathrm{F} \mathrm{VIII}^{-}$ \\
\hline
\end{tabular}

HPF, high power field; CD, cluster of differentiation; Bcl, B-cell lymphoma; EMA, epithelial membrane antigen; CAM, low molecular weight cytokeratin; CEA, carcinoembryonic antigen; MMP, matrix metalloproteinase; SMMS, smooth muscle myosin; CK, creatine kinase.

CD99, vimentin and Bcl-2 expression are important markers for the diagnosis of an SFT.
Our review of previously reported cases in the literature suggests complete surgical resection is generally accepted 
as the definitive and effective treatment of choice for intrapulmonary SFTs. Adequate wedge resection, anatomic segmentectomy and lobectomy, according to the location of mass, are common surgical procedures for resection of intrapulmonary tumours. In our study, three patients underwent adequate wedge resection, whereas the other two patients under anatomic lobectomy. In recent decades, with the development of minimally invasive technology, surgical approaches have been radically changed. More and more intrapulmonary tumours can be safely and availably excised via VATS. In our study, two patients underwent VATS. Previous studies have used radiotherapy and radiofrequency ablation for intrapulmonary SFTs. However, these treatments carry a higher risk of death during follow-up. The effectiveness and capability of such treatment has yet to be confirmed.

Due to their deficiency of information and their languages of publication (not English), some studies were not included in our study. Thirty-six of 681 cases and 8 of 88 cases were SFTs of the lung and pleura, respectively, in Choi's et al (64) and Schirosi's et al (65) studies, and these were not included. Gonullu et al (66) reported a case of metastatic breast carcinoma to SFT in the lung, and Strickland et al (67) reported a case of SFT of the uterus presenting with lung metastases. Míguez González et al (68) reported a case of intrapulmonary SFT associated with haemoptysis, and Masuda et al (69) report two cases of intrapulmonary tumours with different growth patterns. However, the articles were not written in English. Radulescu et al (70) reported a case of malignant primary intrapulmonary SFT with haemangiopericytoma-like features.

In conclusion, we retrospectively reviewed the records of 5 patients with primary intrapulmonary SFTs who underwent surgical resection, and we systematically reviewed previously reported cases in the literature. This study has 4 important findings. First, intrapulmonary SFTs can occur in people of all ages and with no sex predominance. The male-to-female ratio was 1.0:0.96. Second, intrapulmonary SFTs are often discovered incidentally. When symptomatic, the common symptoms are chest pain and cough. Third, the left lower lobe was the most common site location. Finally, complete surgical resection is a safe, effective and successful treatment.

\section{References}

1. Rosado-de-Christenson ML, Abbott GF,McAdams HP,Franks TJ and Galvin JR: From the archives of the AFIP: Localizedfibrous tumorsof the pleura. Radiographics 23: 759-783, 2003.

2. Hanau CA and Miettinen M: Solitary fibrous tumor: Histological and immunehistochemical spectrum of benign and malignant variants presenting at different sites. Hum Pathol 26: 440-449, 1995.

3. Mathew GA, Ashish G, Tyagi AK, Chandrashekharan R and Paul RR: Solitary fibrous tumor of nasal cavity: A case report. Iran J Otorhinolaryngol 27: 307-312, 2015.

4. Rhee SJ, Ryu JK, Han SA and Won KY: Solitary fibrous tumor of the breast: A case report and review of the literature. J Med Ultrason (2001) 43: 125-128, 2016.

5. Bosković T, Zivojinov M, Sabo JI, Budakov Z, Veljković R and Zivojinov S: Rare solitary fibrous tumor of the stomach: A case report. Vojnosanit Pregl 72: 1035-1038, 2015.

6. Huang W, Xu X, Hu J, Cheng G and Xie P: Primary solitary fibrous tumor of the bronchus: A case report. Int J Clin Exp Pathol 8: 13596-13600, 2015.

7. Fu S, Tian Z, Zhang C and He Y: Monosotic fibrous dysplasia and solitary intramuscular myxoma of the head and neck: A unique presentation of Mazabraud's syndrome and a literature review. Oncol Lett 10: 3087-3094, 2015.
8. Silvanto A, Karanjia ND and Bagwan IN: Primary hepatic solitary fibrous tumor with histologically benign and malignant areas. Hepatobiliary Pancreat Dis Int 14: 665-668, 2015.

9. Zhu XS, Dai YC and Chen ZX: Giant solitary fibrous tumor of esophagus resected by endoscopic submucosal dissection. Ann Thorac Surg 100: 2340-2343, 2015.

10. Gao C, Zhang Y, Li YY, Yu YH, Qu W, Gao YS and Zhang S: Postoperative recurrence solitary fibrous tumor of the pelvic with malignant transformation. Int J Clin Exp Med 8: 16827-16833, 2015.

11. Baxter AR, Newman E and Hajdu CH: Solitary fibrous tumor of the pancreas. J Surg Case Rep 2015: rjv144, 2015.

12. Yang W, Sun F, Liu H, Wang G, Shi P, Shao Z and Guo F: Solitary fibrous tumors of the prostate: A case report. Oncol Lett 10: 1617-1619, 2015.

13. Genc A, Toktas Z, Azman C, Bozkurt SU and Kilic T: Solitary fibrous tumor of the orbit: A case report and review of the literature. Turk Neurosurg 25: 984-987, 2015.

14. Kim JH, Yang KH, Yoon PH and Kie JH: Solitary fibrous tumor of central nervous system: A case report. Brain Tumor Res Treat 3: 127-131, 2015

15. Yu R and Rebello R: Solitary fibrous tumor of the parotid gland: A case report. Iran J Otorhinolaryngol 27: 401-405, 2015.

16. Abeygunasekera AM, Ginige AP and Liyanage IS: A solitary fibrous tumor of the kidney. J Cancer Res Ther 11: 662, 2015.

17. Kawaguchi K, Taniguchi $\mathrm{T}$, Usami $\mathrm{N}$ and Yokoi $\mathrm{K}$ : Intrapulmonary solitary fibrous tumor. Gen Thorac Cardiovase Surg 59: 61-64, 2011.

18. Yang X, Jiang Q and Yu B: Solitary fibrous tumor located in the sella turcica: A report of two cases and review of the literature. Oncol Lett 10: 354-358, 2015.

19. Taguchi S: Primary cardiac solitary fibrous tumors. Ann Thorac Cardiovasc Surg 21: 329-331, 2015.

20. Walker CT, Amene CS, Pannell JS, Santiago-Dieppa DR, Rennert RC, Hansen LA and Khalessi AA: Hemorrhagic intramedullary solitary fibrous tumor of the conus medullaris: Case report. J Neurosurg Spine 23: 438-443, 2015.

21. Urabe M, Yamagata Y, Aikou S, Mori K, Yamashita H, Nomura S, Shibahara J, Fukayama M and Seto Y: Solitary fibrous tumor of the greater omentum, mimicking gastrointestinal stromal tumor of the small intestine: A case report. Int Surg 100: 836-840, 2015.

22. Freiser ME, Castaño JE, Whittington EE, Arnold DJ and Sidani CA: Solitary fibrous tumor of the infratemporal fossa. J Radiol Case Rep 8: 1-8, 2014

23. Dozier J, Jameel Z, McCain DA, Hassoun P and Bamboat ZM: Massive malignant solitary fibrous tumor arising from the bladder serosa: A case report. J Med Case Rep 9: 46, 2015.

24. Hyodo R, Komada T, Takada A, Kawai H, Ito S, Nishida Y and Naganawa S: Solitary fibrous tumors in the extremities: Imaging findings for six patients. Nagoya J Med Sci 77:167-178, 2015.

25. Kanazawa T, Kodama K, Nokubi M, Gotsu K, Shinnabe A, Hasegawa M, Kusaka G and Iino Y: A case of solitary fibrous tumor arising from the palatine tonsil. Ear Nose Throat J 94: $117-120,2015$

26. Ge W, Yu DC, Jiang CP and Ding YT: Giant solitary fibrous tumor of the diaphragm: A case report and review of literature. Int J Clin Exp Pathol 7: 9044-9049, 2014.

27. Nishida K, Ubukata H, Konishi S, Shimazaki J, Yano Y, Morishita Y and Tabuchi T: A giant solitary fibrous tumor of the mesentery: A case report and literature review. World J Surg Oncol 13: 17, 2015.

28. Basaran R, Kaksi M, Onoz M, Balkuv E and Sav A: Intradural solitary fibrous tumor of the lumbar spine: A distinctive case report. Case Rep Neurol Med 2015: 708472, 2015.

29. Tsubochi H, Endo T, Sogabe M, Endo S, Morinaga S and Dobashi Y: Solitary fibrous tumor of the thymus with variegated epithelial components. Int J Clin Exp Pathol 7: 7477-7484, 2014.

30. de Oliveira DH, Albuquerque AF, de Araújo Barreto MD, Nonaka CF, da Silva JS, Germano AR and Queiroz LM: Large solitary fibrous tumor of the oral cavity-report of a case. Pathol Res Pract 210: 1064-1067, 2014.

31. Hu S, Yi L, Yang L and Wang Y: Solitary fibrous tumor of the spermatic cord: A case report and literature review. Exp Ther Med 9: 55-58, 2015.

32. Vaziri M, Molanaei S and Tamannaei Z: Solitary fibrous tumor of the intrathoracic goiter. Med J Islam Repub Iran 28: 51, 2014.

33. Lee W, Jeon SM and Lee SH: Calcifying fibrous tumor of the rectum: A case report. Indian J Pathol Microbiol 57: 504-505, 2014.

34. ChoKJ,RoJY,ChoiJ,ChoiSH,NamSY and KimSY:Mesenchymal neoplasms of the major salivary glands: Clinicopathological features of 18 cases. Eur Arch Otorhinolaryngol 265 (Suppl 1): S47-S56, 2008. 
35. Gold JS, Antonescu CR, Hajdu C, Ferrone CR, Hussain M, Lewis JJ, Brennan MF and Coit DG: Clinicopathologic correlates of solitary fibrous tumors. Cancer 94: 1057-1068, 2002.

36. Alobid I, Bernal-Sprekelsen M, Benitez P, Moragas M and Nadal A: Solitary fibrous tumor of the larynx. Otolaryngol Head Neck Surg 133: 163-165, 2005.

37. Shim YS, Choi SJ, Kim HS and Lee JI: Solitary fibrous tumor of the trachea: CT findings with a pathological correlation. Korean J Radiol 9: 286-289, 2008.

38. Prévot S, Penna C, Imbert JC, Wendum D and de Saint-Maur PP: Solitary fibrous tumor of the adrenal gland. Mod Pathol 9: 1170-1174, 1996.

39. Biedrzycki OJ, Singh N, Habeeb H, Wathen N and Faruqi A Solitary fibrous tumor of the female genital tract a case report and review of the literature. Int J Gynecol Pathol 26: 259-264, 2007.

40. O'Connel JX, Logan PM and Beauchamp CP: Solitary fibrous tumors of the periosteum. Hum Pathol 26: 460-462, 1995.

41. Plönes T, Kayser G and Passlick B: Solitary malignant fibrous tumor of the mediastinum. Asian Cardiovasc Thorac Ann 21: 491-492, 2013

42. Thompson CF, Bhuta SM and Abemayor E: Solitary fibrous tumor of the hypopharynx: Case report and literature review. Am J Otolaryngol 34: 545-547, 2013.

43. Cardinale L, Ardissone F, Cataldi A, Familiari U, Solitro F and Fava C: Solitary fibrous tumor of the lung: Three rare cases of intraparenchymal nodules. Acta Radiol 50: 379-382, 2009.

44. Ikeda T, Wada N, Nomura M, Tamiya S and Ushijima M: A case of solitary fibrous malignant tumor with multiple metastases. Nihon Kokyuki Gakkai Zasshi 49: 913-916, 2011 (In Japanese).

45. Sironi M, Rho B and Spinelli M: Adenofibromatous pattern in a solitary fibrous tumor of the lung. Int J Surg Pathol 13: 79, 2005.

46. Dong A, Zuo C, Wang Y and Cui Y: Enhanced CT and FDG PET/CT in malignant solitary fibrous tumor of the lung. Clin Nucl Med 39: 488-491, 2014.

47. van de Rijn M, Lombard CM and Rouse RV: Expression of CD34 by solitary fibrous tumors of the pleura, mediastinum and lung. Am J Surg Pathol 18: 814-820, 1994.

48. Demırağ F, Cakir E and Alpar S: Expression of CD44 and MMP-2: Possible association with histopathological features of pleuro-pulmonary solitary fibrous tumors. Am J Surg 18 814-820, 1994

49. Barrettara B, Napoli G, Lacitignola A and Sardelli P: Fibrous lung tumor: A peculiar case. J Thorac Dis 5: E179-E180, 2013

50. Patsios D, Hwang DM and Chung TB: Intraparenchymal solitary fibrous tumor of the lung: An uncommon cause of a pulmonary nodule. J Thorac Imaging 21: 50-53, 2006.

51. Sakurai H, Tanaka W, Kaji M, Yamazaki K and Suemasu K: Intrapulmonary localized fibrous tumor of the lung: A very unusual presentation. Ann Thorac Surg 86: 1360-1362, 2008

52. Sagawa M, Ueda Y, Matsubara F, Sakuma H, Yoshimitsu Y, Aikawa H, Usuda K, Minato H and Sakuma T: Intrapulmonary solitary fibrous tumor diagnosed by immunohistochemical and genetic approaches: Report of a case. Surg Today 37: 423-425, 2007.

53. Geramizadeh B, Banani A, Moradi A, Hosseini SM and Foroutan H: Intrapulmonary solitary fibrous tumor with bronchial involvement: A rare case report in a child. J Pediatr Surg 45: 249-251,2010.

54. Rao N, Colby TV, Falconieri G, Cohen H, Moran CA and Suster S: Intrapulmonary solitary fibrous tumors: Clinicopathologic and immunohistochemical study of 24 cases. Am J Surg Pathol 37: 155-166, 2013.
55. Caruso RA, LaSpada F, Gaeta M, Minutoli I and Inferrera C: Report of an intrapulmonary solitary fibrous tumor: Fine-needle aspiration cytologic findings, clinicopathological and immunohistochemical features. Diagn Cytopathol 14: 64-67, 1996.

56. Fridlington J, Weaver J, Kelly B and Kelly E: Secondary hypertrophic osteoarthropathy associated with solitary fibrous tumor of the lung. J Am Acad Dermatol 57 (Suppl 5): S106-S110, 2007.

57. Kouki HS, Koletsis EN, Zolota V, Prokakis C, Apostolakis E and Dougenis D: Solitary fibrous tumor of the lung. Gen Thorac Cardiovasc Surg 56: 249-251, 2008.

58. Baliga M, Flowers R, Heard K, Siddiqi A and Akhtar I: Solitary fibrous tumor of the lung: A case report with a study of the aspiration biopsy, histopathology, immunohistochemistry and autopsy findings. Diagn Cytopathol 35: 239-244, 2007.

59. Khalifa MA, Montgomery EA, Azumi N, Gomes MN, Zeman RK, Min KW and Lack EE: Solitary fibrous tumors: A series of lesions, some in unusual sites. South Med J 90: 793-799, 1997.

60. Chang YL, Lee YC and Wu CT: Thoracic solitary fibrous tumor: Clinical and pathological diversity. Lung Cancer 23: 53-60, 1999.

61. Musyoki FN, Nahal A and Powell TI: Solitary fibrous tumor: An update on the spectrum of extrapleural manifestations. Skeletal Radiol 41: 5-13, 2012

62. Klemperer P and Rabin CB: Primary neoplasms of the pleura. A report of five cases. Arch Pathol 11: 385-412, 1931

63. Yan J, Jones RL, Lewis DH and Eary JF: Impact of (18)F-FDG PET/CT imaging in therapeutic decisions for malignant solitary fibrous tumor of the pelvis. Clin Nucl Med 38: 453-455, 2013

64. Choi IH, Song DH, Han KM, Choi YS and Han J: Incidence of pulmonary non-epithelial tumors: 18 years' experience at a single institute. Pathol Res Pract 210: 210-216, 2014.

65. Schirosi L, Lantuejoul S, Cavazza A, Murer B, Yves Brichon P, Migaldi M,Sartori G,Sgambato A and Rossi G: Pleuro-pulmonary solitary fibrous tumors: A clinicopathologic, immunohistochemical and molecular study of 88 cases confirming the prognostic value of de Perrot staging system and p53 expression and evaluating the role of c-kit, BRAF, PDGFRs (alpha/beta), c-met and EGFR. Am J Surg Pathol 32: 1627-1642, 2008.

66. Gonullu G, Sullu Y, Basoglu A, Elmali M, Karaoglanoglu M and Yucel I: Metastatic breast carcinoma to solitary fibrous tumor in the lung. Indian J Cancer 47: 76-78, 2010.

67. Strickland KC, Nucci MR, Esselen KM, Muto MG, Chopra S, George S and Howitt BE: Solitary fibrous tumor of the uterus presenting with lung metastases: A case report. Int J Gynecol Pathol 35: 25-29, 2016

68. Míguez González J, Varona Porres D, Andreu Soriano J and Montero Fernández MÁ: Intrapulmonary solitary fibrous tumor associated with hemoptysis: A case report. Radiologia 54: 182-186, 2012 (In Spanish).

69. Masuda R, Tanaka I, Inoue M, Furuhata Y and Takemura T: Two cases of a solitary fibrous tumor with different growth patterns. Nihon Kyobu Geka Gakkai Zasshi 44: 2177-2182, 1996 (In Japanese)

70. Radulescu D, Pripon S, Ciuleanu TE and Radulescu LI: Malignant primary pulmonary tumor with hemangiopericytoma-like features: Conventional hemangiopericytoma versus solitary fibrous tumor. Clin Lung Cancer 8: 504-508, 2007.

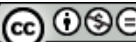

This work is licensed under a Creative Commons Attribution-NonCommercial-NoDerivatives 4.0 International (CC BY-NC-ND 4.0) License. 